\title{
Window Management for Energy Conservation ${ }^{1}$
}

Marie Hammer ${ }^{2}$

Windows can provide light, ventilation and an enjoyable view. However, they also can make heating and cooling your home more difficult. On a hot day, more energy will come through just one square foot of clear glass than through an entire insulated wall. Between 20 to 50 percent of the total energy loss in a well-insulated structure occurs through and around the windows and doors.

The key to the problem is window management -- using windows to provide heat or coolness when needed, and covering them when they allow too much hot or cold air to enter. Heat always travels to a cooler surface, so you must block the flow of heat. You can be energy conscious and still create an aesthetic and efficient plan to manage windows.

Florida's long air-conditioning season and short heating season increase the importance of protecting windows, walls and sliding glass doors during hot weather. However, you still will want to allow solar heat to enter your home during cold weather, so you need flexible window treatments. According to the Florida Solar
Energy Center, good shading strategies can save 10 to 20 percent of your cooling and heating energy.

\section{Shading from the Outside}

The most effective method of preventing solar energy from entering windows is by shading from the outside.

The effectiveness of the various treatments varies with the method of construction, window type and method of installation.

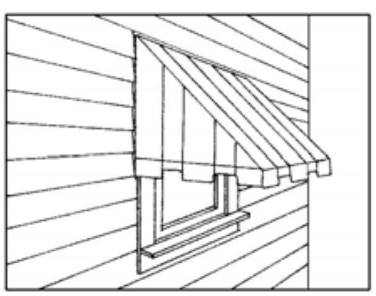

A long, deep overhang on the roof of the house can protect your windows from high summer sunrays, but still allow lower winter sunrays to enter and provide extra warmth. What can you do if your roof does not provide this protection? Canvas or aluminum awnings, exterior shutters, blinds or solar screens also work well to provide shading. Bamboo or other roll-up shades will provide some protection from the sun. Shading from trees, trellises and

1. This document is FCS 3091, one of a series of the Department of Family, Youth and Community Sciences, Florida Cooperative Extension Service, Institute of Food and Agricultural Sciences, University of Florida. Publication date: February 2003. First published: January 1988. Reviewed: February 2003 Please visit the EDIS Web site at http://edis.ifas.ufl.edu

2. Written by Marie Hammer, former Professor, Housing/Home Environment, Department of Family, Youth and Community Sciences, Cooperative Extension Service, Institute of Food and Agricultural Sciences, University of Florida, Gainesville, 32611 and reviewed by Nayda I. Torres, Professor, Family and Consumer Economics, Department of Family, Youth and Community Sciences, Cooperative Extension Service, Institute of Food and Agricultural Sciences, University of Florida and Dale Dorman, Extension Housing and Environment Specialist - Emeritus, Cooperative Extension Service, University of Georgia. 
trellised vines are also very effective. Preventing sunlight from entering at all is the best method, because once short sunrays pass through glass and are absorbed by furnishings, they change into long rays that will not pass back out through the glass. Therefore, they add heat to your room.

\section{Using Interior Window Treatments}

If you cannot protect your windows with outdoor shading, try to achieve a comfortable room temperature and decrease the glare by using interior window treatments. You do not have to sacrifice with these window treatments since they can be very smart looking as well as functional.

\section{Mechanical Window Treatments}

- Roller shades that are an opaque, lightcolored vinyl and are hung close to the glass, but allow air space, are one of the best ways to prevent solar heat from


entering a room. Mount the shades on the inner portion of the window frame. Pull the shades down to cover the window during the day. The shades can also be mounted on the outer edge of the window frame and sealed with magnetic tape or velcro.

Shades that are translucent, or see-through, will let more heat and light pass into a room. Darker shades will absorb heat, and not be as effective as the light, opaque shades. Heavy vinyl or reflective materials are more efficient than plain fabrics. Shades can be particularly attractive when combined with draw draperies, louvered shutters, folding screens or Venetian blinds.

- Venetian blinds can be used to admit some light by deflecting it to the ceiling without admitting direct sunrays. The effectiveness of Venetian blinds depends on how much the slats are left open and the degree to which the edges are sealed. Blinds that are tightly closed during summer days will reduce

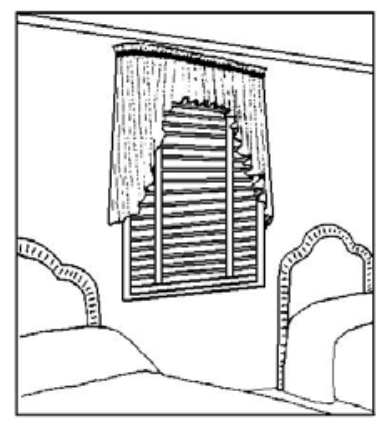
heat gain, while those open at a 45 degree angle will be about half as effective as a closed blind. Some standard-sized mini-blinds have reflective surfaces on the outside.



- Single-layer pleated shades are available in a number of materials ranging from heavy parchment paper, to shades with aluminized back coatings for reflecting summer sun. New

opaque fabrics are available if privacy is more important than view.

- Vinyl verticals have become popular for sun control. Their effectiveness is related to the color you select and how well the individual vanes touch when closed. They should come as close to the floor as possible and have a closed top or ceiling mount.

- Honeycomb-pleated shades are made of two layers of materials with an air space inside, which creates an insulation layer. These shades can be purchased with or without sealed edges and can be used alone or with other treatments. They are available in an assortment of finishes, including a white metalized finish. The amount of summer

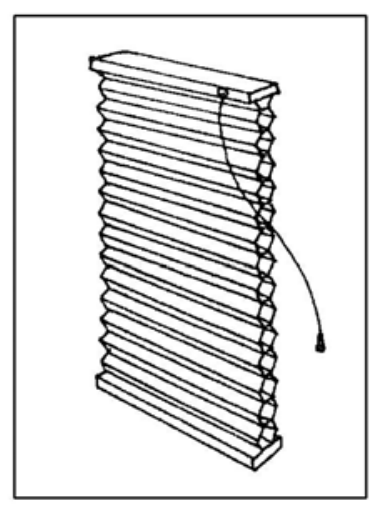


heat reduction will depend on the finish and how well the edges are sealed.

- Woven-wood shades with tightly woven yarns and a tight mount are more efficient than standard woven woods. Shades are available with a clear film on the backside that fills the spaces and increases efficiency. Light colors reflect more summer sun than dark colors. Wovens combine well with other window treatments.

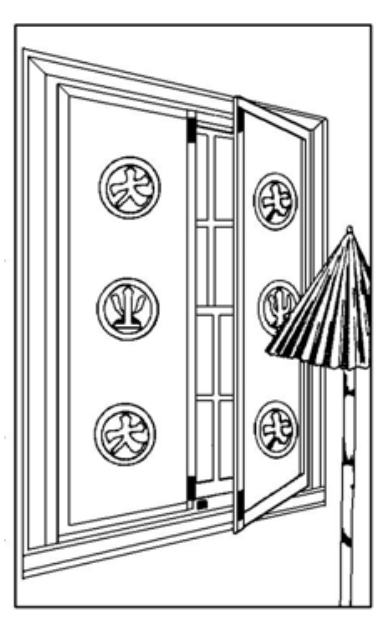

- Shutters are available in a variety of styles, including louvered, padded fabric or solid wood. They can also be made from foam, or several layers of corrugated cardboard or plywood. Their efficiency depends on whether they are kept closed and are mounted snugly in the window. Weatherstripping will make them more effective.

\section{Creating Fabric-Insulated Window Treatments}

In order for fabric window treatments to be energy efficient, they must be resistant to heat transfer by using multiple layers, reflective surfaces and air spaces for insulation. They must be designed to control airflow in the window area, and provide a vapor barrier in high humidity areas. Sealing the edges of the window treatment to the window increases energy efficiency.

- Roman shades are good for improving energy efficiency, and are attractive and versatile. They have a built-in top seal, and the edges are relatively easy to seal. Roman shades can be made with a number of multi-layer combinations. One effective shade is made using a mediumweight, tightly-woven face fabric, a synthetic batting for humid climates, a reflective plastic film, another layer of batting and a white or off-white lining.

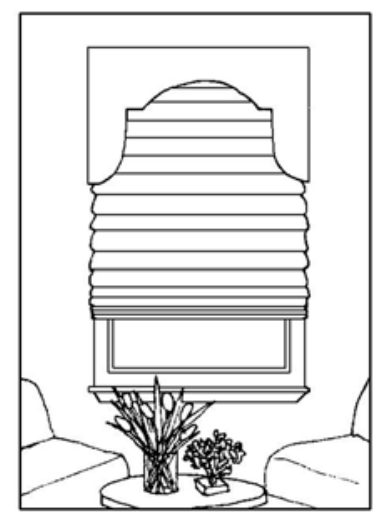

The layers can be quilted horizontally and vertically to form the pleat locations. If mounted inside the window, the shade can be made a couple of inches wider than the opening so the excess can be tucked in to touch the frame when the shade is down. Velcro or flexible magnetic tape can be used to secure the edges. When mounting on the outside of the window, magnetic tape or Velcro can be used to seal the shade when in the down position.

- Insulated roll-ups can be purchased or hand-made. Quick and easy roll-up shades can be made from quilted bedspreads or quilts. They are made the size of the window, and can be mounted on the outside with velcro or magnetic tracks. Roll down to reduce heat gain

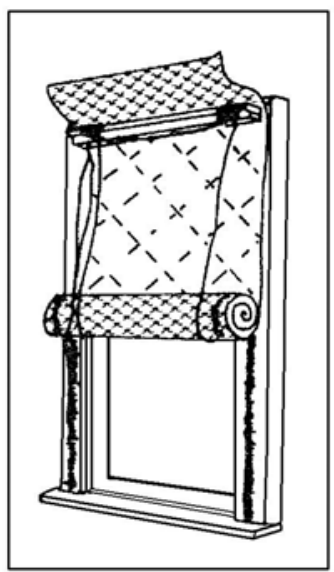
and roll up and tie for a decorative treatment.

- Pinch-pleated draperies that are lightcolored, tightly-woven and lined help control and reduce solar heat gain. To prevent heat from moving into a cooler surface, mount your drapery rods so the draperies hang close to the windows. Close off the top of the drapery by using a closed-top cornice, 
valance or lambrequin, or by hanging the draperies so the top extends to the ceiling.

Drapery length should be below the window sill, or better yet, to the floor. Attaching the sides of the drapery to the wall or window frame with snaps or velcro also cuts down on the airflow over the window. Allow draperies to overlap well in the center when drawn, and keep draperies closed during the day. Drapery linings can help block out more heat, especially if they are white or light colored. White will reflect some heat before it enters the room. Lightcolored draperies with white plastic backing will reduce summer heat gain.

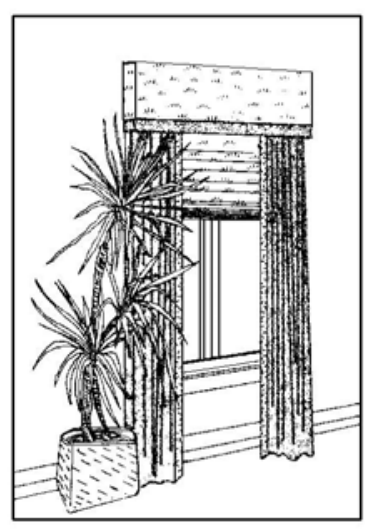

\section{- Cornices and valances} with closed tops stop air currents from dropping in behind other window treatments. In contemporary interiors, cornices can be made to fit flush inside the window frame to coordinate with roller shades, blinds, curtains or shutters.

- Lambrequins are cornices with long sides that usually go to the floor. They provide both a top and side seal, while adding a decorative touch.

\section{General Hints For Your Treatments}

- Consider how much sun enters each window. Good management of all types of window treatments is the key. For summer, east and west windows need greater protection from sunlight than north and south windows. In winter, south windows can capture solar heat and reduce heating loads, so the window treatments should be open during the day, and closed when the sun goes down.

- Color affects heat absorption. Dark colors absorb more heat than light colors. Shiny surfaces reflect more light than flat or dull surfaces.

- Loosely woven fabrics allow light to enter but provide privacy. However, they will also allow more heat to enter during the summer and more heat to be lost during the winter.

- Reducing solar heat gain by a specific percentage, such as 50 percent, does not mean that your energy costs will be reduced by that percentage. The heat that is added to a room by sunlight is only one factor of heat gain. Other factors affecting the amount of heat in a room include: warm air entering through the cracks and air spaces; heat carried through walls and ceilings; heat generated by lighting, equipment, the number of people and activities in the room; and the amount of humidity present. All these factors need to be considered and controlled to help reduce total energy costs. 